\title{
Clusters ou Sistemas Locais de Produção: Mapeamento, Tipologia e Sugestões de Políticas*
}

\author{
Clusters or Local Production Systems: \\ Mapping, Classification and Suggestions for Polices
}

WILSON SUZIGAN**
JOÃO FURTADO $* * *$
RENATO GARCIA $* * * *$
SÉRGIO SAMPAIO $* * * *$

RESUMO: Este trabalho se propõe a avançar ainda mais no desenvolvimento de uma metodologia para mapeamento, classificação e caracterização de Sistemas Locais de Produção (SPL) no Brasil. Tal esforço se justifica não apenas pela importância que esses sistemas vêm acumulando para a geração de empregos e bem-estar social, crescimento econômico, exportações e desenvolvimento tecnológico, mas também pela atenção que recebem de diversos organismos públicos e instituições privadas, muitas vezes desprovidos de metodologia adequada. resultando em dispersão de esforços e desperdício de recursos públicos e privados. Portanto, o principal objetivo do trabalho é fornecer evidências que permitam racionalizar critérios de gestão de políticas públicas e ações privadas direcionadas ao LPS, oferecendo sugestões de políticas e ações diferenciadas segundo categorias ou tipos de sistemas com características distintas de acordo com sua relevância para o local ou desenvolvimento regional, bem como sua importância no contexto do setor em que estão inseridos.

PALAVRAS-CHAVE: Sistemas de produção local; aglomerados industriais; mapeamento; políticas publicas.

\footnotetext{
* Este artigo é uma versão modificada de trabalho apresentado no XXXI Encontro Nacional de Economia da ANPEC - Associação Nacional de Centros de Pós-graduação em Economia, Porto Seguro, 10-13 de dezembro de 2003. Os autores agradecem o apoio do CNPq por meio de auxílio-pesquisa, Processo 466034/2000-8, bem como de Bolsas PIBIC para as estagiárias Ana Paula Munhoz Cerrón e Maíra Aymone Rodrigues.

* * Instituto de Geociências da Universidade Estadual de Campinas - UNICAMP, Campinas/SP, Brasil. E-mail: wsuzigan@ige.unicamp.br.

*** Professor do Departamento de Engenharia de Produção da Escola Politécnica da USP, coordenador do Observatório de Estratégias para a Inovação, São Paulo/SP. Brasil, e-mail: jfurt@uol.com.br.

***** Professor do Departamento de Engenharia de Produção da Escola Politécnica da Universidade de São Paulo - USP, São Paulo/SP, Brasil, e -mail: renato.garcia@poli.usp.br.

***** Mestrando em Desenvolvimento Econômico, Departamento de Economia, Universidade Federal do Paraná - UFPR, Curitiba/PR, Brasil, e-mail: seksampa@ufpr.br. Submetido: janeiro 2004; aceito: março 2004
} 
ABSTRACT: This paper sets out to advance further in the development of a methodology for mapping, classifying and characterizing Local Production Systems (LPS) in Brazil. Such effort is justified not only for the importance these systems have been amassing for generating jobs and social welfare, economic growth, exports and technological development, but also for the attention they have received from several public organisms and private institutions, many times lacking adequate methodological criteria, resulting in dispersion of efforts and waste of both public and private resources. Therefore, the main goal of the paper is to provide evidence that allows rationalizing public policies administration criteria and private actions directed to LPS, offering suggestions for policies and actions differentiated according to categories or types of systems with distinct characteristics according to their relevance to local or regional development as well as their importance in the context of the sector in which they are inserted.

KEYWORDS: Local production systems; industrial clusters; mapping; public policies.

JEL Classification: R12; R58; O18.

\section{INTRODUÇÃO}

Este artigo busca apresentar, de forma bastante simplificada e com aplicação específica ao Estado de São Paulo, os resultados de um trabalho mais amplo que procura identificar estatisticamente, mapear geograficamente e caracterizar estruturalmente sistemas locais de produção (SLPs). Esse trabalho representou um primeiro passo numa metodologia abrangente e serviu de base para orientar estudos de casos realizados no âmbito do projeto de pesquisa Sistemas Produtivos Locais na Indústria Calçadista Brasileira: Avaliação e Sugestões de Políticas, realizado em 2001-2003 com apoio financeiro do CNPq. Resultados semelhantes podem evidentemente ser obtidos para outras unidades da Federação, para regiões ou para o país como um todo.

Tal esforço de mapeamento, classificação e caracterização de SLPs justifica-se não só pela importância que esses sistemas vêm adquirindo na geração de empregos e bem-estar social, crescimento econômico, exportações e desenvolvimento tecnológico, como também pela atenção que vêm recebendo de vários órgãos públicos e instituições privadas, muitas vezes sem critérios metodológicos adequados, acarretando dispersão de esforços e desperdício de recursos públicos e privados. ${ }^{1}$ Portanto, o objetivo último deste artigo é trazer evidências que permitam racionalizar critérios de administração de políticas públicas e ações privadas direcionadas aos SLPs, oferecendo sugestões de políticas e ações diferenciadas se-

\footnotetext{
${ }^{1}$ Dentre os órgãos públicos e instituições privadas que se ocupam atualmente de estudos e ações de fomento a SLPs (também denominados como "arranjos produtivos locais", ou ainda clusters) encontramse: SEBRAE nacional e estaduais, BNDES, MCT, MDIC, FINEP, IPEA, secretarias estaduais, FIESP. O SEBRAE nacional, por exemplo, anunciou há pouco a intenção de apoiar 500 clusters em todo o país (cf.: "Sebrae negocia crédito para 500 clusters", Gazeta Mercantil, 06/05/2003).
} 
gundo categorias ou tipos de sistemas com características distintas de acordo com sua relevância para o desenvolvimento local ou regional e sua importância no contexto do setor em que se inserem.

O artigo está organizado da seguinte forma: a seção 1 faz uma rápida caracterização dos SLPs, destacando sua relevância do ponto de vista de implementação de políticas públicas; a seção 2 comenta brevemente alguns aspectos da metodologia adotada; a seção 3 apresenta os resultados do mapeamento e da classificação dos SLPs ou APLs em algumas categorias ou tipos básicos para implementação de políticas; a seção 4 sugere um roteiro para estudos de casos; a seção 5 discute diretrizes de políticas adaptadas a cada tipo de SLP; e a seção 6 apresenta algumas considerações finais.

\section{SISTEMAS LOCAIS DE PRODUÇÃO: BREVE CARACTERIZAÇÃO E RELEVÂNCIA PARA POLÍTICAS PÚBLICAS}

Sistemas locais de produção podem ter variadas caracterizações conforme sua história, evolução, organização institucional, contextos sociais e culturais nos quais se inserem, estrutura produtiva, organização industrial, formas de governança, logística, associativismo, cooperação entre agentes, formas de aprendizado e grau de disseminação do conhecimento especializado local. Por isso, definir tais sistemas não é tarefa trivial nem isenta de controvérsias. Uma definição bastante difundida é a que foi adotada pela RedeSist — Rede de Pesquisa em Sistemas Produtivos e Inovativos Locais ${ }^{2}$ - , que propõe dois conceitos distintos: (1) “arranjos produtivos locais são aglomerações territoriais de agentes econômicos, políticos e sociais — com foco em um conjunto específico de atividades econômicas - que apresentam vínculos mesmo que incipientes. Geralmente, envolvem a participação e a interação de empresas - que podem ser desde produtoras de bens e serviços finais até fornecedoras de insumos e equipamentos, prestadoras de consultoria e serviços, comercializadoras e clientes, entre outros - e suas variadas formas de representação e associação. Incluem também diversas outras instituições públicas e privadas voltadas para: formação e capacitação de recursos humanos (como escolas técnicas e universidades); pesquisa, desenvolvimento e engenharia; política, promoção e financiamento", e (2) "sistemas produtivos e inovativos locais são aqueles arranjos produtivos em que interdependência, articulação e vínculos consistentes resultam em interação, cooperação e aprendizagem, com potencial de gerar o incremento da capacidade inovativa endógena, da competitividade e do desenvolvimento local. Assim, consideramos que a dimensão institucional e regional constitui elemento crucial do processo de capacitação produtiva e inovativa. Diferentes contextos, sistemas cognitivos e regulató-

${ }^{2}$ Cf.: Cassiolato \& Lastres (2003:27). Ver também o sítio http://www.ie.ufrj.br/redesist/. 
rios e formas de articulação e aprendizado interativo entre agentes são reconhecidos como fundamentais na geração e difusão de conhecimentos e particularmente aqueles tácitos. Tais sistemas e formas de articulação podem ser tanto formais quanto informais".

Note-se que a ordenação desses dois conceitos foi mudada pela RedeSist, que anteriormente adotava um conceito mais geral de sistema produtivo local e outro, definido como conceito auxiliar, de arranjos produtivos locais. Estes seriam aglomerações produtivas cujas articulações entre agentes locais não são suficientemente desenvolvidas para caracterizá-los como sistemas. Sem a pretensão de criar polêmicas conceituais ou discussões de cunho semântico, e embora concordando com a essência da definição atualmente adotada pela RedeSist, optou-se neste artigo pela utilização de um conceito único e simples de sistema local de produção, seguindo a tradição de estudos de pesquisadores italianos ${ }^{3}$ e considerando que as distinções conceituais entre os sistemas resumem-se a graus variados de desenvolvimento, de integração da cadeia produtiva, de articulação e interação entre agentes e instituições locais, e de capacidades sistêmicas para a inovação.

Tais aglomerações de empresas e instituições têm como característica essencial a capacidade de gerar economias externas, incidentais ou deliberadamente criadas, que contribuem para o incremento da competitividade das empresas e, em conseqüência, de todo o sistema local de produção. De fato, as economias externas estão no centro da discussão sobre os sistemas locais. Elas podem ser incidentais, decorrentes de (i) existência de um vasto contingente de mão-de-obra especializada e com habilidades específicas ao sistema local; (ii) presença e atração de um conjunto de fornecedores especializados de matéria-prima, componentes e serviços, e (iii) grande disseminação dos conhecimentos, habilidades e informações concernentes ao ramo de atividade dos produtores locais.

As economias externas de caráter incidental foram apontadas por A. Marshall em seu estudo pioneiro dos distritos industriais ingleses. Além das economias externas incidentais, entretanto, os agentes locais (empresas e instituições) podem reforçar sua capacidade competitiva por meio de ações conjuntas deliberadas, tais como compra de matérias-primas, promoção de cursos de capacitação gerencial e formação profissional, criação de consórcios de exportação, contratação de serviços especializados, estabelecimento de centros tecnológicos de uso coletivo e cooperativas de crédito, entre outras. A conjugação das economias externas incidentais com as obtidas por ações conjuntas deliberadas resulta na chamada "eficiência coletiva", principal determinante da capacidade competitiva das empresas locais (Schmitz e Nadvi, 1999).

Em geral, um sistema local de produção comporta um conjunto de empresas com capacidades relacionadas ou afins, de portes variados, mas normalmente com

\footnotetext{
${ }^{3}$ Ver sobretudo Belussi \& Gottardi (2000) e Lombardi (2003).
} 
um conjunto expressivo de pequenas e médias empresas não integradas verticalmente. Essas empresas, por sua vez, atraem fornecedores e outras indústrias correlatas e de apoio, cuja presença e importância nos sistemas locais são determinadas exclusivamente por forças de mercado. Por fim, surgem também importantes instituições locais de apoio à empresas.

Pelo potencial que apresentam do ponto de vista de políticas de desenvolvimento regional/local, e mesmo de políticas industriais, as aglomerações geográficas e setoriais de empresas têm sido objeto de estudos e de medidas de políticas públicas, tanto no Brasil como em outros países. Todavia, nota-se uma carência, mais evidente no caso do Brasil, de critérios metodológicos que permitam identificar, delimitar geograficamente e caracterizar sistemas ou arranjos produtivos locais segundo alguns tipos básicos, de acordo com sua relevância para o desenvolvimento regional/local e sua importância no respectivo setor ou classe de indústria. Este é um passo fundamental para nortear medidas de políticas e ações privadas, e é nesse sentido que este trabalho pretende contribuir.

\section{BREVES COMENTÁRIOS SOBRE A METODOLOGIA}

Em trabalhos anteriores dos autores ${ }^{4}$ foi desenvolvida uma metodologia para identificação, delimitação geográfica e caracterização estrutural de SLPs por meio da utilização do coeficiente de Gini locacional e de um índice de especialização, o quociente locacional (QL), combinados com variáveis de controle e filtros. Tal metodologia foi aplicada a dados de emprego e de produção do estado de São Paulo, utilizando as bases de dados da RAIS/MTE e da PIA/IBGE. Essa metodologia foi aplicada a alguns estudos de casos, apresentados nos mesmos trabalhos de forma meramente ilustrativa.

Neste trabalho, pretende-se avançar na mesma direção apresentando um mapeamento de SLPs no estado de São Paulo. A partir da aplicação da metodologia desenvolvida nos outros trabalhos, ou seja, utilizando o coeficiente de Gini locacional e o QL, e aplicando o número de estabelecimentos e a participação na classe industrial no estado de São Paulo como variáveis de controle, ${ }^{5}$ busca-se identificar o número de aglomerações de empresas industriais de acordo com critérios mais ou menos restritivos. Essa tarefa reveste-se de grande importância inclusive para a definição de instrumentos mais finos de políticas de apoio aos sistemas locais.

Neste artigo, a referida metodologia será aplicada às informações de emprego da RAIS/MTE, base de dados que tem sido bastante utilizada para a caracteriza-

\footnotetext{
${ }^{4}$ Ver, entre outros, Suzigan et al. (2003a e 2003b).

${ }^{5}$ Vale reiterar que tal metodologia pode ser aplicada a outros estados da federação, a regiões mais amplas e mesmo para o país como um todo.
} 
ção de sistemas locais de produção. ${ }^{6}$ A principal vantagem da RAIS para essa metologia é justamente a elevada desagregação setorial e geográfica dos dados. Isto torna possível, sem necessidade de recurso a tabulações especiais, obter e processar diretamente os dados desagregados, em termos espaciais, até o nível de municípios e, em termos setoriais, até o nível de classes de indústrias a 4 dígitos da CNAE - Classificação Nacional da Atividade Econômica.

Porém, essas vantagens são contrabalançadas por algumas deficiências, que já foram apontadas por diversos autores, inclusive os autores deste trabalho. Dentre os principais problemas da RAIS, deve-se destacar sua cobertura, que inclui apenas relações contratuais formalizadas, a autoclassificação das empresas na coleta das informações primárias, e a dificuldade de classificação de empresas multiplantas, que podem declarar todo o emprego em uma mesma unidade, e multiprodutos, que podem inserir todas as informações na atividade principal.

Utilizando os dados do ano de 2000 da RAIS, foram calculados os mencionados indicadores de concentração (Gini locacional) e de especialização (QL) regional de atividades econômicas, instrumentos já bastante conhecidos e utilizados em estudos e análises de economia regional. O primeiro passo, tal como o fizeram Krugman (1991) e Audretsch \& Feldman (1996), ${ }^{7}$ foi calcular o coeficiente de Gini locacional.

O coeficiente de Gini locacional indica a concentração espacial da atividade econômica e foi calculado para 267 classes da indústria de transformação do estado de São Paulo. ${ }^{8}$ Varia entre zero e um, e quanto mais próximo da unidade, mais espacialmente concentrada é a classe de indústria. Isto significa que nas classes em que o Gini é mais elevado podem existir sistemas locais de produção.

Porém, o coeficiente de Gini locacional indica apenas que determinada classe de indústria é geograficamente concentrada; não permite verificar a existência de sistemas locais de produção. Para isso, é necessário um segundo passo: num corte analítico regional, utiliza-se o quociente locacional (QL) para verificar em quais regiões se localizam as atividades das classes de indústrias mais concentradas em termos geográficos. O quociente locacional é a razão entre a participação de uma determinada classe de indústria na estrutura produtiva de uma certa re-

\footnotetext{
${ }^{6}$ Muitos autores já utilizaram essa base de dados com propósitos semelhantes. Por afinidade com este artigo, cumpre mencionar, entre outros, Brito (2003), Brito e Albuquerque (2001), Albuquerque et al. (2002), Diniz \& Crocco (1996) e Saboia (2001).

${ }^{7}$ Krugman (1991) calculou o coeficiente de Gini locacional para medir a concentração espacial da indústria dos Estados Unidos a três dígitos, e Audrescht e Feldman (1996) utilizaram esse mesmo indicador para verificar as relações entre a concentração geográfica das atividades inovativas e a localização da atividade industrial nos Estados Unidos.

${ }^{8}$ Ressalte-se que, de um total de 296 classes de indústrias, foram calculados coeficientes de Gini locacional para 267 classes, já que 29 delas apresentaram zero empregados em 2000. Somos gratos ao Prof. Rodolfo Hoffman, do IE/UNICAMP, por sua ajuda na elaboração da metodologia de cálculo dos coeficientes de Gini locacional com base na RAIS.
} 
gião e a participação dessa mesma classe na estrutura produtiva do estado. Nesse sentido, quanto maior o QL, maior é a especialização da região na classe de indústria respectiva. Esse indicador foi calculado para as 63 microrregiões geográficas do estado de São Paulo e as mesmas 267 classes de indústrias CNAE 4 dígitos.

Em adição a esses dois indicadores, foram utilizadas algumas variáveis de controle, que serviram de "filtros" para inserir critérios de maior ou menor seletividade nos resultados dos indicadores de concentração (Gini) e de especialização (QL). A utilização dessas variáveis de controle justifica-se por dois motivos principais. Primeiro, porque, em alguns casos, o elevado índice de especialização é uma decorrência da baixa densidade da estrutura industrial local, o que pode levar a uma superestimação da importância do sistema local. Para solucionar esse problema, utiliza-se a participação relativa da microrregião no estado de São Paulo naquela determinada classe industrial, o que dimensiona a sua importância econômica. ${ }^{9}$ Segundo, essas variáveis de controle permitem verificar se o elevado QL de uma determinada região não é mera decorrência da presença local de uma grande empresa, o que não caracterizaria um SLP. Para isso, foram utilizadas as informações sobre número de estabelecimentos, o que permite verificar se se trata efetivamente de uma aglomeração com um número significativo de empresas. ${ }^{10}$ Nesse sentido, eliminam-se microrregiões em que a elevada especialização, demonstrada pela existência de um QL elevado, decorre da presença de uma ou poucas empresas de maior porte.

\section{RESULTADOS}

Os resultados da aplicação da metodologia acima aos dados de emprego da RAIS/2000 referentes ao estado de São Paulo, segundo as 63 microrregiões geográficas e 267 classes da indústrias CNAE 4 dígitos do estado, são resumidos nesta seção. Primeiramente, a tabela 1 mostra a estatística descritiva das informações que foram utilizadas para a elaboração dos coeficientes de Gini locacional.

\footnotetext{
${ }^{9}$ Para esse fim poderia ser utilizado, alternativamente, o volume de emprego na microrregião naquela determinada classe industrial, o que também demonstra a sua importância econômica.

${ }^{10}$ Deve-se observar que, neste ponto, os dados da RAIS apresentam um problema, já que eles não informam o número de empresas, mas sim o de estabelecimentos, o que pode trazer distorções à análise se em alguma determinada região as empresas possuírem diversas plantas, que seriam contadas mais de uma vez nas informações sobre número de estabelecimentos.
} 
Tabela 1: Estatística descritiva dos coeficientes de Gini locacional para o emprego nas classes de indústrias e microrregiões do estado de São Paulo

\begin{tabular}{cc}
\hline & Estatística \\
\hline Amostra & 267 \\
Média & 0,6303 \\
Desvio Padrão & 0,1789 \\
Variância & 0,0320 \\
Amplitude & 0,7781 \\
Mínimo & 0,2018 \\
Máximo & 0,9799 \\
\hline
\end{tabular}

Fonte: elaboração dos autores.

Os resultados apontam um largo espectro de variação dos coeficientes de Gini locacional, que vai de 0,20 até 0,98 . A partir desses resultados, um primeiro critério é o de desprezar as classes de indústrias que apresentam coeficiente menor ou igual a 0,5. Estatisticamente, a concentração geográfica é verificada nas classes de indústrias com coeficiente de Gini locacional maior que 0,5. A tabela 2 mostra a freqüência de casos (classes de indústrias) por faixas de coeficientes de Gini locacional.

Tabela 2: Freqüência de casos para faixas de coeficientes de Gini locacional (GL) para o emprego nas classes de indústrias e microrregiões do estado de São Paulo

\begin{tabular}{ccccc}
\hline Faixa de Gini Locacional & $\mathrm{N}^{\circ}$ de Classes & $(\%)$ & Freqüência acumulada & $(\%)$ \\
\hline $0,90<\mathrm{GL} \leq 1,00$ & 25 & $9,4 \%$ & 25 & $9,4 \%$ \\
$0,80<\mathrm{GL} \leq 0,90$ & 33 & $12,4 \%$ & 58 & $21,7 \%$ \\
$0,70<\mathrm{GL} \leq 0,80$ & 30 & $11,2 \%$ & 88 & $33,0 \%$ \\
$0,63<\mathrm{GL} \leq 0,70$ & 31 & $11,6 \%$ & 119 & $44,6 \%$ \\
$0,60<\mathrm{GL} \leq 0,63$ & 20 & $7,5 \%$ & 139 & $52,1 \%$ \\
$0,50<\mathrm{GL} \leq 0,60$ & 66 & $24,7 \%$ & 205 & $76,8 \%$ \\
$0,40<\mathrm{GL} \leq 0,50$ & 36 & $13,5 \%$ & 241 & $90,3 \%$ \\
$0,30<\mathrm{GL} \leq 0,40$ & 21 & $7,9 \%$ & 262 & $98,1 \%$ \\
$0,20<\mathrm{GL} \leq 0,30$ & 5 & $1,9 \%$ & 267 & $100,0 \%$ \\
Total & 267 & $100 \%$ & & \\
\hline
\end{tabular}

Fonte: elaboração dos autores.

Pelos dados da tabela 2 percebe-se que 205 classes de indústrias 4 dígitos apresentam coeficiente de Gini locacional superior a 0,5, o que indica que essas classes apresentam algum grau de concentração geográfica da produção e do emprego. Notese entretanto que esse grande número de classes com elevado coeficiente de Gini locacional é uma especificidade do estado de São Paulo, que não só é a região mais industrializada do país como também caracteriza-se pela forte concentração 
da indústria na região metropolitana da capital e em seu entorno, que engloba as regiões de Campinas, São José dos Campos, Sorocaba e a Baixada Santista. Essa forte concentração regional de uma estrutura industrial diversificada, ao mesmo tempo em que certamente estimula o surgimento de sistemas locais de produção, torna difícil identificá-los estatisticamente, como se discute adiante.

Diante desse grande número de classes de indústrias com algum grau de concentração geográfica no estado, procurou-se tornar mais seletiva a identificação de aglomerações de empresas que se configurem como sistemas locais de produção por meio da utilização de filtros ou variáveis de controle por microrregião. Isso é feito em duas etapas. Primeiro, num corte analítico por classes de indústrias, procura-se verificar o número de classes geograficamente concentradas em uma ou mais microrregiões segundo diferentes combinações de filtros. O número de casos possíveis vai depender, é claro, do maior ou menor rigor dos filtros. Segundo, num corte por microrregiões, procura-se verificar o número de classes de indústrias regionalmente concentradas em cada microrregião. Este último passo permite verificar se as microrregiões selecionadas têm estruturas produtivas que configurem sistemas locais de produção.

Os filtros utilizados baseiam-se em um conjunto de três variáveis:

- o quociente locacional (QL), que indica o grau de concentração relativa de uma classe de indústria em determinada microrregião, ou a especialização produtiva da microrregião;

- a participação relativa da microrregião em determinada classe de indústria no total do emprego da classe no estado de São Paulo;

- o número de estabelecimentos da classe de indústria na microrregião.

A primeira etapa da aplicação desses filtros é apresentada na tabela 3. Os resultados mostram um conjunto de casos possíveis, cuja amplitude depende do grau de restritividade dos filtros, para identificação de aglomerações de empresas em classes de indústrias nas microrregiões do estado de São Paulo. É importante observar que ainda não se trata da identificação de SLPs, mas sim do número de casos de classes de indústrias com coeficientes de Gini locacional maior que 0,5 que, conforme a combinação de filtros utilizada, apresentam-se concentradas em uma 
ou mais microrregiões. ${ }^{11}$ Para identificar SLPs, é necessário o corte analítico por microrregião, como se faz adiante.

Tabela 3: Número de classes industriais concentradas em uma ou mais microrregiões (MR) segundo diferentes combinações de filtros ou variáveis de controle

\begin{tabular}{llccccc}
\hline \multirow{2}{*}{\begin{tabular}{l} 
No Estab \\
\cline { 2 - 6 }
\end{tabular}} & QL & \multicolumn{5}{c}{$\begin{array}{c}\text { Participação da MR no total do } \\
\text { emprego da classe maior ou igual a }\end{array}$} \\
& & $\ldots$ & $5 \%$ & $10 \%$ & $20 \%$ & $40 \%$ \\
\hline \multirow{2}{*}{..} & Maior do que 1 & 1713 & 713 & 432 & 233 & 119 \\
& Maior do que 2 & 1141 & 565 & 354 & 173 & 68 \\
& Maior do que 5 & 570 & 354 & 235 & 122 & 53 \\
\hline Maior ou igual a 10 & Maior do que 1 & 250 & 187 & 138 & 102 & 55 \\
& Maior do que 2 & 154 & 120 & 83 & 53 & 15 \\
& Maior do que 5 & 75 & 65 & 42 & 24 & 7 \\
\hline Maior ou igual a 20 & Maior do que 1 & 115 & 102 & 83 & 69 & 47 \\
& Maior do que 2 & 64 & 54 & 37 & 27 & 12 \\
& Maior do que 5 & 35 & 33 & 20 & 12 & 5 \\
\hline Maior ou igual a 50 & Maior do que 1 & 51 & 47 & 40 & 35 & 22 \\
& Maior do que 2 & 23 & 21 & 15 & 12 & 4 \\
& Maior do que 5 & 16 & 15 & 10 & 7 & 2 \\
\hline
\end{tabular}

Fonte: elaboração dos autores.

Como se pode ver, se os critérios de restritividade dos filtros forem pouco restritivos, o número de casos pode chegar a 1.713 classes de indústrias com concentrações geográficas de empresas em microrregiões do estado de São Paulo. Mesmo levando em conta que, em geral, os SLPs concentram várias classes de indústrias inter-relacionadas, esse seria um indicador evidentemente exagerado. À medida que os critérios se tornam mais restritivos, o número de casos vai se reduzindo.

Neste artigo, optou-se por estabelecer critérios mais restritivos, uma vez que o objetivo é apenas o de demonstrar a aplicação da metodologia. Portanto, visando identificar e caracterizar aglomerações de empresas como SLPs, estabeleceu-se que, para classes de indústrias com Gini locacional maior que 0,5 , a microrregião satisfaça todos os seguintes parâmetros dos filtros:

- apresentar um quociente locacional superior a 2;

- ser responsável por pelo menos $1 \%$ do total do emprego da respectiva classe de indústria no estado;

- ter pelo menos 20 estabelecimentos da mesma classe de indústria.

\footnotetext{
${ }^{11}$ O total de casos possíveis é de 12.915, dado pelo número de classes industriais com Gini locacional maior que 0,5 (205), multiplicado pelo número de microrregiões (63).
} 
O resultado da combinação desses critérios foi a identificação de 64 classes de indústrias nas quais há aglomerações de empresas em várias microrregiões do estado de São Paulo. Antes de verificar se essas aglomerações de empresas em microrregiões do estado constituem sistemas locais de produção (corte por microrregião), as 64 classes foram organizadas por categorias de acordo com o grau de especialização da microrregião na respectiva classe, dado pela magnitude do QL, e com o peso da participação da microrregião no total do emprego da classe no estado de São Paulo. Os resultados apresentados na tabela 4 mostram as 64 classes de indústrias distribuídas em quatro tipos de aglomerações. ${ }^{12}$

Tabela 4: Número de classes de indústrias segundo diferentes combinações de filtros

\begin{tabular}{|c|c|c|c|}
\hline \multirow[t]{2}{*}{ QL } & \multicolumn{3}{|c|}{ Participação da MR no total do emprego da classe industrial (4 dig.) } \\
\hline & $P \leq 10 \%$ & $P>10 \%$ & Total \\
\hline$>5$ & 15 & 20 & 35 \\
\hline $2<\mathrm{QL} \leq 5$ & 12 & 17 & 29 \\
\hline TOTAL & 27 & 37 & 64 \\
\hline
\end{tabular}

Fonte: elaboração dos autores.

A seguir, para verificar se essas aglomerações se configuram como sistemas locais de produção, procurou-se identificar quais são as microrregiões correspondentes às classes de indústrias em cada uma das quatro categorias da classificação acima proposta. Começando pelo quadrante superior direito, que engloba 20 classes industriais, fortemente concentradas em microrregiões, com QL maior que 5 e participação maior que $10 \%$ no total do emprego da classe, verifica-se que se tratam de aglomerações que podem ser caracterizadas como de elevada importância para a região $(\mathrm{QL}>5)$ e, ao mesmo tempo, muito importantes para a respectiva classe de indústria no estado de São Paulo (participação > 10\% no emprego da classe), como mostra a tabela 5. As aglomerações nesse caso podem ser chamadas de núcleos de desenvolvimento setorial-regional.

No quadrante superior esquerdo da tabela 4, encontram-se 15 classes de indústrias em microrregiões com QL maior que 5, mas com participação inferior a $10 \%$ no total do emprego da classe no estado. Portanto, tratam-se de aglomerações muito importantes para a região, mas pouco importantes para a respectiva classe de indústria no estado. Aglomerações desse tipo foram chamadas de vetores de desenvolvimento local e são mostradas na tabela 6 .

\footnotetext{
${ }^{12}$ Os dados completos das aglomerações identificadas, organizados por classes da indústrias e microrregiões geográficas, podem ser obtidos no site http://geein.fclar.unesp.br/atividades/pesquisacluster/ cluster3.htm.
} 
Tabela 5: Número de classes de indústrias em microrregiões do estado de São Paulo na categoria "núcleo de desenvolvimento setorial-regional"

\begin{tabular}{cccc}
\hline Microrregiões & $N^{\circ}$ de classes & Microrregiões & $N^{\circ}$ de classes \\
\hline São José do Rio Preto & 1 & Pirassununga & 1 \\
Franca & 4 & São João da Boa Vista & 1 \\
Ribeirão Preto & 1 & Mogi-Mirim & 1 \\
Birigüi & 2 & Campinas & 1 \\
Jaú & 1 & Amparo & 1 \\
Piracicaba & 1 & São José dos Campos & 1 \\
Araraquara & 1 & Itapeva & \\
Limeira & 2 & &
\end{tabular}

Fonte: elaboração dos autores.

Tabela 6: Número de classes de indústrias em microrregiões do estado de São Paulo na categoria "vetor de desenvolvimento local"

\begin{tabular}{cccc}
\hline Microrregiões & $N^{0}$ de classes & Microrregiões & $N^{\circ}$ de classes \\
\hline São José do Rio Preto & 1 & Bauru & 1 \\
Campos do Jordão & 1 & Ourinhos & 1 \\
Dracena & 1 & Mogi-Mirim & 1 \\
Birigüi & 1 & Capão Bonito & 1 \\
Jaú & 3 & Amparo & 1 \\
Araraquara & 1 & Tatuí & 1 \\
Votuporanga & 1 & & \\
\hline
\end{tabular}

Fonte: elaboração dos autores.

O terceiro quadrante da tabela 4 mostra que 17 classes de indústrias foram classificadas em microrregiões que, embora apresentem QL inferior a 5, o que significa que essas classes de indústrias são relativamente pouco importantes em termos da estrutura produtiva local, têm elevada participação no total do emprego da classe, o que significa que são muito importantes para a respectiva classe no estado. Essas aglomerações são típicas das regiões metropolitanas e de áreas em que se verificam elevada densidade industrial e diversificação da estrutura produtiva, e foram denominadas como vetores avançados. Sobressaem-se as microrregiões de São Paulo e de Campinas, como mostra a tabela 7. 
Tabela 7: Número de classes de indústrias em microrregiões

do estado de São Paulo na categoria "vetores avançados"

\begin{tabular}{cccc}
\hline Microrregiões & $N^{0}$ de classes & Microrregiões & $N^{0}$ de classes \\
\hline São Paulo & 7 & Campinas & 8 \\
Limeira & 1 & São José dos Campos & 1 \\
\hline
\end{tabular}

Fonte: elaboração dos autores.

Por fim, no quadrante inferior esquerdo da tabela 4 aparecem 12 classes de indústrias em microrregiões nas quais os respectivos QLs e participações no total do emprego mostram que tais aglomerações são pouco importantes tanto para a economia local quanto para a classe de indústria no estado. Essas aglomerações foram chamadas de embriões de sistemas locais de produção. O elevado rigor dos filtros utilizados fez com que o número de classes de indústrias nessa categoria fosse menor do que nos outros casos. Porém, uma pequena atenuação dos filtros, por exemplo, a redução do número mínimo de estabelecimentos de 20 para 10, faria aumentar para 37 o número de classes de indústrias nessa categoria.

Tabela 8: Número de classes de indústrias em microrregiões do estado de São Paulo na categoria "embrião de sistema local de produção"

\begin{tabular}{cccc}
\hline Microrregiões & $N^{\circ}$ de classes & Microrregiões & $N^{\circ}$ de classes \\
\hline Ourinhos & 2 & Jaú & 1 \\
Bragança Paulista & 2 & Botucatu & 1 \\
Ribeirão Preto & 1 & Pirassununga & 1 \\
Rio Claro & 1 & Mogi-Mirim & 1 \\
Limeira & 2 & & \\
\hline
\end{tabular}

Fonte: elaboração dos autores.

Um passo adicional, não empreendido neste artigo por razões de espaço, seria o de voltar para o indicador QL e, para as microrregiões identificadas como SLPs, especialmente aquelas com maior número de classes de indústrias, adotar o corte por microrregião e, ignorando os filtros, agregar todas as classes com QL acima de 1. Isto permitiria identificar as classes de indústrias correlatas presentes na microrregião, caracterizar a estrutura produtiva local e, quando for o caso, avaliar aproximadamente a extensão da cadeia produtiva, determinando assim a configuração do sistema local de produção.

\section{OS SISTEMAS LOCAIS: ROTEIRO PARA ESTUDOS DE CASO}

A metodologia apresentada acima é bastante eficiente na tarefa de identificação de aglomerações geográficas de empresas e na delimitação de sistemas locais 
de produção, possibilitando inclusive caracterizar em linhas gerais a estrutura produtiva local. Entretanto, como foi mencionado antes, a aplicação dessa metodologia é apenas um passo prévio, embora essencial, para selecionar as aglomerações mais relevantes que podem ser objeto de estudos de casos. Estes últimos são imprescindíveis para orientar ações de apoio e medidas de políticas públicas. Somente com a pesquisa de campo é possível captar as especificidades de cada uma das aglomerações de empresas, sua história, evolução, forma de organização industrial, instituições de apoio, estrutura de governança e outras características relevantes.

Nesse sentido, os estudos de casos de sistemas locais de produção devem trabalhar em dois planos de análise: primeiro, no nível agregado, do sistema como um todo, e segundo, no nível das empresas que o compõem. Em cada um desses planos a coleta de dados e informações por meio de entrevistas e visitas a empresas e instituições locais deve cobrir um conjunto de pontos de investigação, detalhados a seguir. ${ }^{13}$

\section{Empresas}

- Caracterização da empresa (fundação, localização, tamanho, propriedade do capital).

- Principais produtos, volume de produção, mercados (interno, externo).

- Canais de comercialização.

- Fatores que diferenciam o produto da empresa (preço, qualidade, marca, design, serviços pós-venda, prazos de entrega).

- Desenvolvimento interno de produtos (departamento de P\&D, percentual de gastos em relação ao faturamento, número e qualificação das pessoas envolvidas, diferenciação mercado interno/mercado externo no desenvolvimento de produtos)

- Fontes de informação para desenvolvimento de produtos/design.

- Desenvolvimento de produtos por terceiros (local, regional, nacional, internacional).

- Relações cooperativas/associativas com outras empresas do mesmo ramo e com instituições de apoio.

- Localização dos principais fornecedores.

- Interação com fornecedores de matérias-primas, componentes, máquinas.

\footnotetext{
${ }^{13}$ Esses pontos resultam da aplicação, por parte da equipe de pesquisa do projeto CNPq já mencionado, de questionários que serviram de roteiro para entrevistas e visitas a empresas e instituições. Os pontos foram sendo aperfeiçoados à medida que os estudos de casos eram aplicados. Até meados de 2003, haviam sido realizados nove estudos de casos com aproximadamente 150 visitas/entrevistas.
} 
- Política da qualidade dos produtos (programas, certificações, testes).

- Fontes de financiamento para expansão de capacidade, capital de giro, desenvolvimento de produtos.

\section{Sistema local de produção como um todo}

- Extensão territorial (cidade/região), localização, logística em relação a mercados de produtos e de insumos, população, emprego.

- História e condições iniciais.

- Evolução.

- Organização institucional (instituições de apoio, associações de classe, serviços especializados).

- Estrutura de produção e abrangência da cadeia produtiva: especialização, divisão de trabalho, distribuição por tamanho das empresas, inter-relações produtivas das empresas, inserção nos mercados interno e internacional, estruturas de governança presentes no sistema (coordenação das relações de poder entre as empresas).

- Formas de aprendizado/disseminação de conhecimentos especializados locais.

- Contextos sociais, culturais e políticos.

A partir de estudos de casos selecionados pela metodologia quantitativa aqui proposta e que sigam o roteiro de pontos acima sugerido, é possível caracterizar o sistema local e as empresas que o compõem de forma a indicar, com bastante segurança, quais seriam as ações de apoio e as medidas de políticas mais promissoras para resolver problemas específicos e estimular o crescimento da produção, o aumento do emprego, as exportações, o desenvolvimento tecnológico e outros objetivos relevantes em cada caso, inclusive aqueles relacionados a objetivos sociais.

\section{POLÍTICAS}

Um dos desafios colocados pelo renascimento, recente, das forças favoráveis à adoção de uma política industrial é o de dar respostas às necessidades do desenvolvimento econômico de uma forma ao mesmo tempo democrática e compatível com as restrições de recursos - sem dúvida, muito mais importantes do que as prevalecentes nos anos de ouro das políticas industriais (nos anos de 1950 e 1970).

Esta dupla exigência condiciona sobremaneira a engenharia das políticas industrial e de desenvolvimento. Para ter acentuado o seu caráter democrático, a política deve oferecer oportunidades a diferentes setores e, sobretudo, deve contribuir para o desenvolvimento de regiões menos favorecidas; mas ao mesmo tempo, pa- 
ra poder sustentar-se no quadro atual de restrições, ela deverá ser econômica e eficiente, quer dizer, gastar poucos recursos e, com eles, alcançar resultados efetivos. Combinar amplas oportunidades com escassez de recursos constitui uma tarefa tão importante quanto difícil.

A metodologia aqui proposta pretende ser uma contribuição a um tal esforço de política industrial. Os sistemas locais de produção possuem características que permitem alçá-los à condição de vetores de desenvolvimento - setorial, regional e social. Ademais, podem oferecer valiosa contribuição também para o esforço de dar sustentação ao balanço de pagamentos, na medida em que possam ter as suas capacidades de produção complementadas com novos atributos comerciais e que elas sejam direcionadas para novos mercados.

Se existe uma ampla concordância quanto à importância dos sistemas locais de produção, ela é sem dúvida muito menor no que diz respeito à quantificação e qualificação dessas configurações econômicas setoriais e regionais. Quantos SLPs existem no Brasil ou numa região? Que importância possuem eles e quais são as suas principais características? Perguntas como essas têm recebido respostas pouco sistemáticas, e os seus resultados são, muitas vezes, irregulares ou mesmo contraditórios.

A partir da metodologia desenvolvida e com base nos resultados obtidos, este estudo permite o mapeamento de alguns tipos básicos de SLPs. Os resultados foram obtidos para o estado de São Paulo, mas podem, sem qualquer dificuldade adicional, ser estendidos para outras regiões brasileiras ou para o país como um todo.

Quatro tipos básicos de SLPs podem ser caracterizados, a partir da metodologia apresentada. O primeiro corresponde aos SLPs que se destacam duplamente: pela sua enorme importância para uma região e para o setor de atividade econômica em torno do qual as suas atividades estão nucleadas. É evidente que o sistema local produtor de calçados de Birigüi é importante para a cidade e a região, mas ele concentra também uma fração muito relevante da produção total de calçados infantis de São Paulo (e, nesse caso, do Brasil). O mesmo poderia ser dito de Franca (SP) e Novo Hamburgo (RS), respectivamente para calçados masculinos e femininos; ou de Limeira (SP) para jóias e bijuterias. A dupla importância destes SLPs para uma região e para o setor a que pertencem torna-os núcleos de desenvolvimento setorial-regional.

Ao lado destes SLPs duplamente importantes, existem aqueles que possuem enorme importância para o setor (traduzida na sua participação na produção e no emprego), mas que estão — por assim dizer — diluídos num tecido econômico muito maior e mais diversificado: eles são importantes para o setor, mas o desenvolvimento econômico regional não depende deles de uma forma tão pronunciada. Diversos setores típicos de SLPs possuem fatias elevadas da sua produção e emprego em regiões com tecidos econômicos tão diversificados que a sua contribuição local é, por isso, muito inferior: aquela região é importante para o setor, mas o setor é menos importante para a região. De forma característica, esta ocorrência está associada às 
grandes cidades industrializadas e, sobretudo, às regiões metropolitanas. Esse é tipicamente o caso da indústria do vestuário na região metropolitana de São Paulo. Pelas características desta produção e pelo desenvolvimento de suas funções empresariais complementares à produção, estes SLPs podem ser considerados muito desenvolvidos, inclusive por disporem de recursos complementares bastante significativos, e poderiam ser designados pela expressão vetores avançados.

Se estes sistemas locais são importantes para um setor, mas não o são para uma região, existem outros que se encontram exatamente na condição oposta: são importantes para uma região, embora não possuam uma contribuição decisiva para o setor principal a que estão vinculados. O peso da região de Dracena na atividade produtora de cerâmica estrutural no estado de São Paulo é reduzido, mas alguém pode duvidar da enorme importância que esta atividade possui para a região? Casos como esse podem ser encontrados em atividades de fabricação e confecção de malhas em Amparo, de confecções na região de Campos do Jordão, de móveis em Votuporanga, entre outros exemplos. Esta configuração representa sobretudo um vetor de desenvolvimento local.

Existe, por derradeiro, um tipo de SLP que pode ser caracterizado como aquele que possui pouca importância para o seu setor e convive, na região, com outras atividades econômicas. Ele constitui, por assim dizer, um embrião de sistema local de produção. É o caso de fabricação de calçados de couro em Ourinhos, fabricação de artefatos têxteis e de cerâmicos em Pirassununga e fabricação de máquinas agrícolas em Ribeirão Preto, entre outros.

O quadro 1 mostra uma tipologia de sistemas locais que envolve a combinação de duas variáveis: a importância da atividade econômica para a região (mensurada pelo QL, ou índice de especialização) e a importância da região para o setor (mensurada por meio da participação da microrregião no total do estado de São Paulo naquela classe).

Quadro 1: Tipologia de SLPs de acordo com sua importância para a região e para o estado de São Paulo

\begin{tabular}{|c|c|c|c|}
\hline & & \multicolumn{2}{|c|}{ Importância para o setor } \\
\hline & & Reduzida & Elevada \\
\hline \multirow{2}{*}{$\begin{array}{l}\text { Importância } \\
\text { local }\end{array}$} & Elevada & $\begin{array}{c}\text { Vetor de } \\
\text { desenvolvimento local }\end{array}$ & $\begin{array}{l}\text { Núcleos de desenvolvimento } \\
\text { setorial-regional }\end{array}$ \\
\hline & Reduzida & Embrião de sistema local & Vetores avançados de produção \\
\hline
\end{tabular}

Fonte: elaboração dos autores.

A partir dessa proposta de tipologia, é possível enquadrar os diversos SLPs da indústria de transformação do estado de São Paulo, identificados nas seções anteriores, dentro dos 4 quadrantes. Alguns SLPs de cada tipo são mostrados no quadro 2. 
Quadro 2: Tipologia e exemplos de SLPs no estado de São Paulo

\begin{tabular}{|c|c|c|c|}
\hline & \multicolumn{2}{|c|}{ Importância para o setor } \\
\hline & & Reduzida & Elevada \\
\hline \multirow{2}{*}{$\begin{array}{l}\text { Importância } \\
\text { local }\end{array}$} & Elevada & $\begin{array}{c}\text { Araraquara Artef. têxteis } \\
\text { Amparo tecidos de malha } \\
\text { Campos do Jordão Malharias } \\
\text { Dracena Cerâmica } \\
\text { Jaú Artef. de couro } \\
\text { Votuporanga Móveis } \\
\text { São José do Rio Preto Jóias }\end{array}$ & $\begin{array}{l}\text { Franca Calçados de couro } \\
\text { Jaú Calçados de couro } \\
\text { Birigüi Calçados de plástico } \\
\text { Limeira Folheados e bijuterias } \\
\text { Ribeirão Preto Equip. médicos } \\
\text { S. José Campos Mat. eletrônico }\end{array}$ \\
\hline & Reduzida & $\begin{array}{c}\text { Ourinhos Calçados de couro } \\
\text { Pirassununga Cerâmica } \\
\text { Limeira Máquinas-ferramenta } \\
\text { Mogi-Mirim Cerâmica } \\
\text { Ribeirão Preto Máquinas agrícolas }\end{array}$ & $\begin{array}{c}\text { Campinas Têxtil } \\
\text { Campinas Telecom./Equips. óticos } \\
\text { São Paulo Vestuário } \\
\text { São Paulo Edição/impressão } \\
\text { São Paulo Cronômetros/relógios }\end{array}$ \\
\hline
\end{tabular}

Fonte: elaboração dos autores.

Esta caracterização pode ser de valia para a definição, para a multiplicidade de SLPs, de uma política industrial abrangente e consistente. Tantos são os SLPs, no estado de São Paulo, assim como em todo o Brasil, que a política industrial para o desenvolvimento destas configurações deveria valer-se de "pacotes de incentivos" capazes de mobilizar os atores locais para oferecerem respostas ativas e compromissos efetivos. As realizações da política industrial dependem do empenho dos agentes privados e dos atores sociais. Assegurá-lo deve estar incorporado, desde o início, à concepção da política industrial e aos seus instrumentos.

Os núcleos de desenvolvimento setorial-regional desenvolveram-se de forma vigorosa e, quase sempre, possuem uma história longa. Pelas próprias características deste processo de desenvolvimento, possuem uma função industrial-produtiva hiperdesenvolvida relativamente às suas funções comerciais, nelas incluído o marketing. Por isso mesmo, a política industrial mais adequada para a promoção destes sistemas a um patamar superior de desenvolvimento e competitividade inclui uma combinação de funções comerciais e industriais voltadas para a superação da dependência nos canais e nas formas de comercialização e para desenvolvimento de produtos, fixação de marcas, registro de patentes, design, certificações, qualidade.

Superar uma inserção subordinada e uma função de produção voltada para o binômio volume elevado e preço baixo requer um conjunto de desenvolvimentos integrados e consistentes nestas duas dimensões. O "pacote" de política industrial para os sistemas deste tipo deveria incluir estes dois aspectos, tratando-os de forma integrada. Tipicamente, a promoção destes núcleos de desenvolvimento setorial regional incluiria a formação de capacidades técnicas superiores e de forças comerciais autônomas. Aquelas podem ser constituídas como desdobramento 
avançado das estruturas de formação profissional e técnica já existentes, mas estas últimas envolvem a reunião de forças dispersas e a constituição de novas organizações empresariais ou entidades jurídicas.

O embrião de sistema local de produção representa a categoria mais numerosa, embora o número de casos possa ser reduzido se, na metodologia utilizada, os filtros forem muito rigorosos. Se os recursos necessários para a política de fomento ao desenvolvimento destes embriões de SLPs podem ser considerados, em termos individuais, modestos, o seu número e a provável incipiência do tecido local em termos de entidades organizativas envolvem maiores riscos. Por isso mesmo, o pacote de política industrial para estes embriões deveria estar associado a uma sequência concatenada de etapas condicionadas, cada qual demandando contrapartidas locais claras, seja em termos de recursos, seja em termos de envolvimento. Embora estes embriões sejam, em vários aspectos, antípodas do tipo anteriormente descrito (núcleos de desenvolvimento setorial-regional), deveria ser evitada a tentação - errônea - de pretender que eles trilhem de forma linear todos os estágios de desenvolvimento dos seus "predecessores" desenvolvidos. Afinal, estes veteranos encontram-se hoje no "beco" do binômio quantidade elevada e preços reduzidos, cuja superação não é fácil nem está assegurada.

Para evitar esta encruzilhada, a política industrial deveria, desde a partida, estimular os embriões de SLPs a realizar estudos de mercados capazes de ajudálos a identificar segmentos de mercado ou mesmo nichos que pudessem ser atingidos a partir de ações coordenadas de promoção, evitando a simples expansão da capacidade produtiva e a competição para baixo, em direção aos preços e à degradação da qualidade. Para que possam atingir estes segmentos, a política deveria, de forma coordenada, propiciar as condições para a capacitação técnica e produtiva necessária.

Os sistemas englobados na categoria de vetor de desenvolvimento local são aqueles para os quais a política de desenvolvimento está mais habilitada. Por um lado, estes vetores já superaram o estágio embrionário, reunindo, pois, massa crítica suficiente para o reconhecimento de sua importância local. Por outro, não enfrentam ainda as dificuldades inerentes aos núcleos de desenvolvimento setorial-regional, tendo que desbravar terrenos e, possivelmente, corrigir trajetórias. Estando a certa distância desses núcleos, os vetores de desenvolvimento local podem evitar a repetição de erros e identificar mais facilmente novas oportunidades. O seu desafio principal é, com estas oportunidades pontuais, construir trajetórias.

Os vetores avançados, diferentemente das demais configurações enunciadas, dificilmente podem ter as suas políticas assimiladas a uma dimensão predominante de desenvolvimento regional. Afinal, eles representam um peso diminuto em regiões normalmente muito mais desenvolvidas e com características de tecido econômico (e social) diversificado e integrado. Isto não significa, no entanto, que esse tipo de sistema local seja menos estruturado ou que entre os seus elementos constituintes não existam fios - tão concretos quanto possivelmente pouco visíveis - 
de relacionamento e forte vinculação. Ocorre, entretanto, que o tecido econômico circundante possui múltiplos ingredientes que podem ser mobilizados para o desenvolvimento dos elementos constituintes deste vetor avançado, um aspecto que o diferencia, de forma clara, dos vetores de desenvolvimento local e, com mais forte razão, dos demais.

A política de fomento para vetores avançados deve, pois, estar pautada principalmente pela mobilização dos próprios recursos locais que representam a "saída" em relação à inevitável erosão da competitividade que uma inserção em produtos da base do mercado inevitavelmente provocaria nestes sistemas, se eles fossem dependentes de uma provisão de fatores abundantes e baratos em regiões - urbanas, metropolitanas - onde eles são, por certo, muito mais caros.

Os instrumentos de política para cada um destes tipos de SLPs são, evidentemente, muito diferentes. É possível que as atividades a serem pensadas para os embriões de sistemas locais sejam numerosas, mas elas serão, por certo, mais básicas. A experiência de campo indica que, nestes casos, ingredientes básicos como cursos de custos e formação de competências gerenciais podem ter grande utilidade e estar inseridos em etapas iniciais de programas de fomento mais longos e ambiciosos. Em relação aos tipos mais avançados, sejam eles os núcleos ou os vetores, as tarefas de uma política exigem recursos mais volumosos e são, ao mesmo tempo, mais arriscadas em termos dos recursos envolvidos.

Em qualquer dos quatro casos apresentados, a política deveria oferecer condições para que os protagonistas locais — que são as empresas, os empresários, os trabalhadores, as entidades públicas e privadas e o tecido associativo formal ou informal — utilizem a sua capacidade de mobilização em favor do desenvolvimento. Isto significa que a política não pode e não deve substituir-se aos atores locais, como deve evitar, sob risco de fracasso antecipado, medidas que possam entorpecer ou atrofiar o desenvolvimento autônomo do sistema local e de suas forças sociais. Em qualquer política para SLPs, o protagonismo das instituições locais deve preponderar.

Ademais, existe um vetor de política que deveria, desde os estágios iniciais das políticas voltadas para os embriões de sistemas locais de produção, ser definido como prioritário. Reconhece-se habitualmente que os sistemas locais de produção existentes no Brasil desenvolveram de forma limitada os mecanismos de cooperação que, segundo as visões paradigmáticas, caracterizam essas configurações em outros países, sobretudo os europeus e a Itália em especial.

Cooperação, é claro, não se inventa e nem se cria por decreto. Mas a política pode, com a força dos seus incentivos associados ao envolvimento local e aos compromissos coletivamente assumidos, criar condições para o fortalecimento do tecido local e do associativismo, bases da cooperação e de ações coletivas mais efetivas. Por isso, o pacote de incentivos de uma política industrial para os sistemas locais deveria preocupar-se com a criação de espaços e instituições coletivas, com gestão compartilhada, financiados com recursos públicos (decrescentes) e privados 
(crescentes). O estímulo inicial concedido pela política, por meio de competição, deveria exigir de forma explícita e contratual contrapartidas tangíveis e mecanismos institucionais de gestão coletiva e - preferencialmente - compartilhada entre os grupos sociais.

O mecanismo de concorrência entre os diferentes sistemas locais deveria propiciar, para a política de fomento, dois resultados relevantes. O primeiro, seriam contrapartidas tangíveis, na forma de uma fração de recursos locais para os recursos públicos alocados às políticas. Assim, por exemplo, a adesão a um programa de centros de formação técnico-profissional ou a cursos de gestão e administração deveria ser avaliada também pelas contrapartidas locais. O segundo ganho seria a avaliação da adesão local (a priori), que poderia ordenar os pleitos dos sistemas locais, e dos resultados obtidos (a posteriori), definidores de uma continuidade do programa e de suas eventuais reorientações.

No outro extremo do espectro dos SLPs, aqueles dos núcleos de desenvolvimento setorial-regional, o mesmo sistema de concorrência pública pelos recursos oferecidos pela política de fomento deveria suscitar respostas nas duas dimensões — tangíveis e intangíveis. Em relação às primeiras, seria possível imaginar contrapartidas em cada uma das dimensões relevantes do desenvolvimento do sistema local — independentemente de que o sistema, pela(s) sua(s) instituição(ões) coletiva(s), solicite recursos da política de fomento apenas para alguns dos programas oferecidos. Assim, a solicitação de equipamentos coletivos para o desenvolvimento tecnológico deveria estar condicionada a esforços em outras dimensões - por exemplo, formação de recursos humanos e desenvolvimento de novas competências comerciais. Em relação às contrapartidas intangíveis, seria desejável - e é factível — que os projetos submetidos à apreciação das instituições públicas de fomento sejam apreciados a partir de uma visão global do estágio de desenvolvimento do sistema local e da sua estratégia de expansão e desenvolvimento.

\section{CONSIDERAÇÕES FINAIS}

Este artigo procurou avançar na metodologia de identificação, delimitação e avaliação da estrutura produtiva de sistemas locais de produção, tendo em vista oferecer evidências que permitam orientar medidas de políticas públicas e ações privadas de apoio. Nesse sentido, produziu um mapeamento de SLPs no estado de São Paulo, que pode ser feito sem qualquer dificuldade para outros estados e regiões, e sugeriu uma classificação de alguns tipos básicos de SLPs. Para estes, apresentou um conjunto de diretrizes de políticas, diferenciadas conforme o tipo de sistema local de produção.

As políticas de fomento e promoção dos sistemas locais de produção enfrentam dilemas importantes. Por um lado, elas são potencialmente democráticas, assentes que estão, na maior parte dos casos, em pequenas empresas, muitas vezes 
em regiões não metropolitanas, vinculadas a tecidos econômicos e sociais muito mais homogêneos. Por outro lado, no entanto, as políticas e as suas possibilidades podem estar muito aquém da multiplicidade das demandas desses sistemas econômicos, dispersos pelo território. Estes dois elementos deveriam servir de advertência contra efeitos discricionários das políticas e fazer com que elas se orientassem para uma gestão democrática e transparente, a partir de uma definição de critérios gerais igualmente acessíveis a todos os sistemas.

$\mathrm{O}$ interesse da metodologia desenvolvida e aqui apresentada consiste precisamente em propiciar uma estratificação dos sistemas em categorias relativamente homogêneas, para as quais poderiam ser identificados pacotes de estímulos e apoios, que seriam concedidos segundo as contrapartidas propiciadas pelos atores locais. A “disputa" pelos estímulos oferecidos pela política de fomento serviria, assim, para que os sistemas locais, por meio das suas entidades representativas ou de sociedades de propósito específico criadas para essa finalidade, pudessem mobilizar os atores locais para uma atuação mais consistente e efetiva. A política perderia, assim, um eventual elemento discricionário, estimulando respostas ativas e pleitos mais estruturados por parte dos atores locais - ganhos para a política, ganhos também para os sistemas locais.

\section{REFERÊNCIAS BIBLIOGRÁFICAS}

ALBUQUERQUE, E. M.; SIMÕES. R.; BAESSA, A.; CAMPOLINA, B., e SILVA, L. (2002). A distribuição espacial da produção científica e tecnológica brasileira: uma descrição de estatísticas de produção local de patentes e artigos científicos. Revista Brasileira de Inovação, 1 (2): 225-251, janeiro-dezembro.

AUDRESCHT, D.; FELDMAN, M. (1996). R\&D spillovers and the geography of innovation and production. The American Economic Review, v. 86, n. 3, jun.

BELUSSI, F. \& GOTTARDI, G. (2000). Evolutionary Patterns of Local Industrial Systems - towards a cognitive approach to the industrial district. Aldershot: Ashgate.

BRITTO, J. (2003). Configuração espacial da indústria brasileira: uma análise baseada na noção de aglomerações produtivas. Trabalho apresentado no $8^{\circ}$ Encontro da Sociedade Brasileira de Economia Política. Florianópolis, junho.

BRITTO, J. \& ALBUQUERQUE, E. M. (2001). Estrutura e dinamismo de clusters industriais na economia brasileira: uma análise exploratória a partir dos dados da RAIS. In L. F. TIRONI. Industrialização Descentralizada: Sistemas Industriais Locais. Brasília: IPEA, capítulo 1.

DINIZ, C. C. \& CROCCO, M. A. (1996). Reestruturação econômica e impacto regional: o novo mapa da indústria brasileira. Nova Economia, 6 (1), julho.

KRUGMAN, P. (1991). Geography and trade. Cambridge: MIT Press.

LOMBARDI, M. (2003). The evolution of local production systems: the emergence of the "invisible mind" and the evolutionary pressures towards more visible "minds". Research Policy 32 (8): 1443-1462. SABOIA, J. (2001). Desconcentração industrial no Brasil na década de noventa: um processo dinâmico e diferenciado regionalmente. Nova Economia, 11 (2), dezembro.

SCHMITZ, H.; NADVI, K. (1999). Clustering and industrialization: introduction. World Development, v. 27, n. 9, Sep.

SUZIGAN, W.; FURTADO, J.; GARCIA, R.; SAMPAIO, S. (2003a). Coeficientes de Gini locacionais 
— GL: aplicação à indústria de calçados do estado de São Paulo. Nova Economia, Belo Horizonte, 13 (2): 39-60, julho-dezembro de 2003.

SUZIGAN, W.; FURTADO, J.; GARCIA, R.; SAMPAIO, S. (2003b). Local production and innovation systems in the state of São Paulo, Brazil. The 43rd European Congress of the Regional Science Association - ERSA 2003, Jyvaskyla, Finland, 27-30 August. Disponível no site http://econpapers. hhs.se/paper/wiwwiwrsa/ersa03p251.htm. 